\title{
MODEL FASIES GUNUNGAPI \\ DALAM KAITANNYA DENGAN UBAHAN HIDROTERMAL DAN MINERALISASI DI DAERAH SELOGIRI, KABUPATEN WONOGIRI - JAWA TENGAH
}

Oleh :

\author{
Danny Z . Herman \\ Penyelidik Bumi Madya \\ Kelompok Kerja Konsenasi, Pusat Sumber Daya Geologi
}

\section{SAR I}

Secara morfologi daerah Selogiri, Kabupaten Wonogiri-Jawa Tengah dibentuk oleh bentang alam gunung api, pematang pegunungan, perbukitan bergelombang dan dataran aluvium; dimana bentang alam gunungapi terdiri atas depresi sirkular gunungapi (circular volcanic depression), kerucut gunungapi (volcanic cone) dan kompleks batuan beku (igneous complex).

Identifikasi terhadap sekwen perlapisan batuan piroklastik dan lava di wilayah Selogiri menuntun ke arah dugaan bahwa daerah tersebut adalah bagian dari bentang alam gunungapi komposit yang dibentuk oleh kegiatan erupsi gunungapi bersifat eksplosif. Diperkirakan bahwa bentuk depresi sirkular gunungapi berasal dari kaldera yang berperan sebagai pusat erupsi gunungapi.

Analisis model fasies gunungapi di daerah Selogiri dilakukan melalui pengujian secara regional terhadap perubahan lateral dan vertikal suatu sekwen endapan gunungapi. Mengacu kepada klasifikasi fasies menurut William dan McBirney (1972), teridentifikasi bahwa fasies gunungapi terdiri atas central atau vent, proksimal dan distal. Fasies pertama berada di lingkungan depresi sirkular gunungapi/kaldera dengan diameter sebaran mencapai $8 \mathrm{~km}$, yang dibentuk o'eh endapan breksi gunungapi primer, tuf, lava dan terobosan batuan-batuan beku. Fasies kedua tersebar dalam radius $6 \mathrm{~km}$ dari kaldera, dibentuk terutama oleh endapan gunungapi primer/sekunder berupa breksi dan tuf serta lava andesit. Sementara fasies ketiga dibentuk oleh endapan sedimen hasil erosi dan pengendapan kembali, berupa tuf dan batugamping klastik; yang tersebar dalam radius $>5 \mathrm{~km}$ hingga $15 \mathrm{~km}$ dari vent.

Ubahan hidrotermal dan pembentukan mineralisasi emas epitermal yang intensif di daerah Selogiri terjadi pada lingkungan depresi sirkular, yang merupakan indikasi dari fasies central/vent. Hal ini memungkinkan terjadi karena fasies tersebut termasuk kedalam bagian pusat kegiatan vulkanisma, magmatisma dan tektonisma; dimana kegiatan penerobosan batuan beku, pembentukan pola rekahan dan kegiatan hidrotermal sangat berperan sebagai pengendali terjadinya ubahan batuan dan mineralisasi.

\section{PENDAHULUAN}

Pengenalan daerah fasies gunungapi merupakan bagian penting dalam eksplorasi mineral, terutama pada daerah-daerah termineralisasi yang berkaitan dengan kegiatan vulkanisma dan magmatisma. Identifikasi dan pemetaan ciri fisika dari jenis batuan, lingkungan pengendapan dan struktur gunungapi dapat menuntun ke arah pemahaman tentang hubungan proses vulkanisma, magmatisma dan mineralisasi. Beberapa terminologi dibawah ini dapat digunakan untuk konsep pendekatan :
1. Vulkanologi fisik, dapat diartikan sebagai studi tentang mekanisma erupsi, produk dari erupsi gunungapi dan bentangalam yang dihasilkan oleh erupsi gunungapi. Termasuk aspek-aspek ciri fisika dari produk erupsi dan analisis fasies, stratigrafi dan rekonstruksi lingkungan purba (paleoenvironment; Trowell, 1986).

2. Fasies, adalah suatu endapan atau satuan erupsi atau kedua-duanya mempunyai hubungan spatial, geometrik dan ciri internal (Self, 1982d).

3. Siklus kaldera, adalah sekwen kejadian dari perkembangan kaldera dalam pengertian runtuhnya 


\begin{tabular}{|c|c|}
\hline & $\begin{array}{c}\text { Tabel 1. } \\
\text { Produk Gunungapi Yang Berasosiasi Dengan Fasies Gunungapi Komposit } \\
\text { (Menurut William dan MeBirney, 1979) }\end{array}$ \\
\hline & 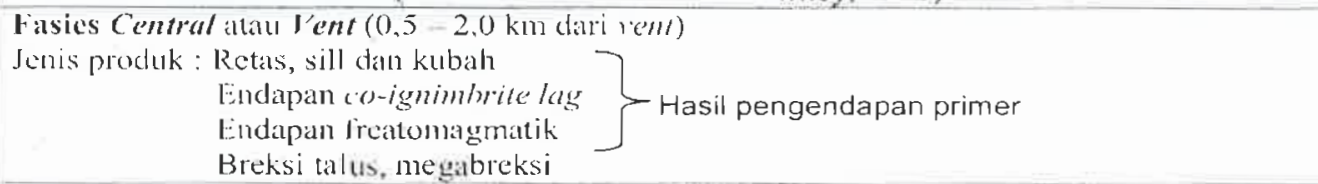 \\
\hline & 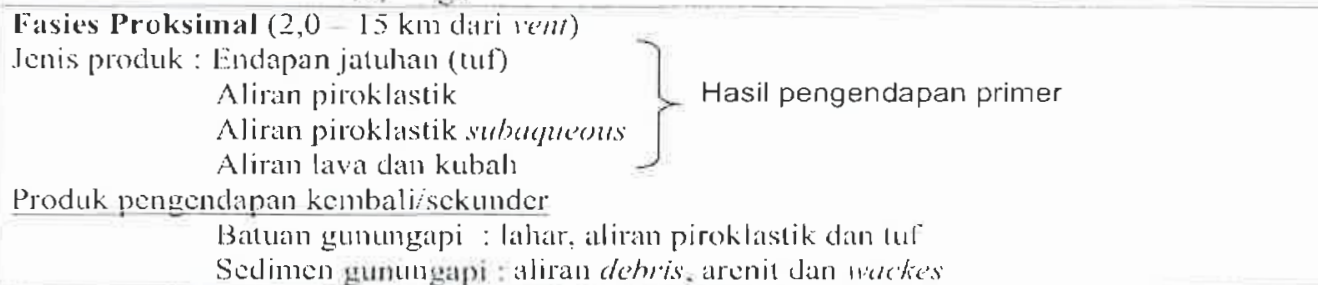 \\
\hline & 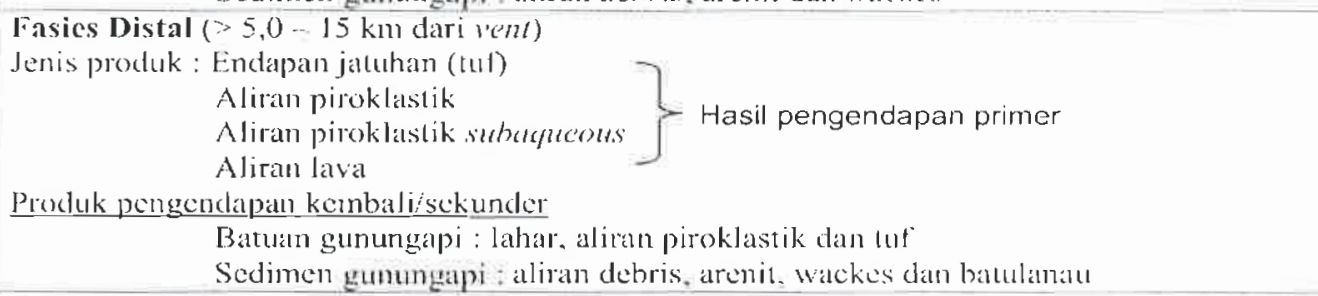 \\
\hline & $\begin{array}{l}\text { Fasies Epiliastik } \\
\text { Jenis produk: Talus dan sedimen debris aliran (di danau kepundin. kolam dian kipas } \\
\text { alluvial), berinterkalasi dengan endapan gunungapi. }\end{array}$ \\
\hline
\end{tabular}

gunungapi (volcano collapse). Kaldera adalah suatu depresi gunungapi berbentuk lingkaran, lebih kurang berbentuk agak melingkar atau lingkaran (William, 1941) dihasilkan oleh runtuhnya penutup dapur magma akibat pengosongan katastropik dari dapur tersebut ketika terjadi erupsi Plinian. Kejadian tersebut akan menghasilkan rekahanrekahan yang berperan sebagai jalan keluar larutan hidrotermal, dan dipercaya mngendapkan urat-urat epitermal mengandung logam mulia.

\section{Mekanisma Erupsi}

Mekanisma erupsi berakibat kepada ciri fisika dari produk-produk gunungapi, bagaimana dan dimana diendapkan; karena itu sejauh mana hal tersebut dapat digunakan sebagai alat eksplorasi. Terdapat 3 (tiga) jenis mekanisma utama erupsi yang dapat dihubungkan dengan ciri fisika produk gunungapi, yaitu :

1. Erupsi freatik (uap panas), dihasilkan ketika air meteorik menguap oleh tekanan yang cukup untuk mempuat rekahan batuan; dan disemburkan melalui rekahan batuan tersebut. Tidak ada bahan juvenile (magmatik) dikeluarkan dalam letusan ini.

2. Erupsi freatomagmatik (surtseyan), dihasilkan oleh interaksi air tanah/permukaan dan magma; yang dapat menyemburkan banyak bahan lithic dan juvenile.

3. Erupsi magmatik. dihasilkan oleh semburan bahan cair di permukaan, baik berupa ledakan atau lelehan yang dibagi lebih jauh menjadi beberapa jenis. Berdasarkan peningkatan intensitas erupsi : basaltic flood, Hawaiian, Strombolian, Volcanian, Sub-Plinian, Plinian dan Ultra-Plinian. Erupsi Plinian biasanya disertai oleh terbentuknya kaldera runtuhan kaldera (caldera collapse).

\section{Produk Erupsi}

Terdapat 2 (dua) jenis endapan yang dihasilkan oleh mekanisma erupsi, yaitu sebagai berikut :

1. Endapan lelehan (ekstrusif), termasuk didalamnya adalah aliran lava dan kubah lava yang dihasilkan selama erupsi magmatik.

2. Endapan eksplosif/piroklastik, yang dapat dihasilkan oleh 3 (tiga) jenis erupsi gunungapi; yaitu endapan jatuhan, aliran dan runtuhan (surge) serta endapan piroklastik lainnya.

\section{Fasies Pada Gunungapi Komposit}

Fasies gunungapi komposit terdiri atas 4 (empat) bagian, yaitu : central atau vent, proksimal, distal dan epiklastik (Tabel 1). 


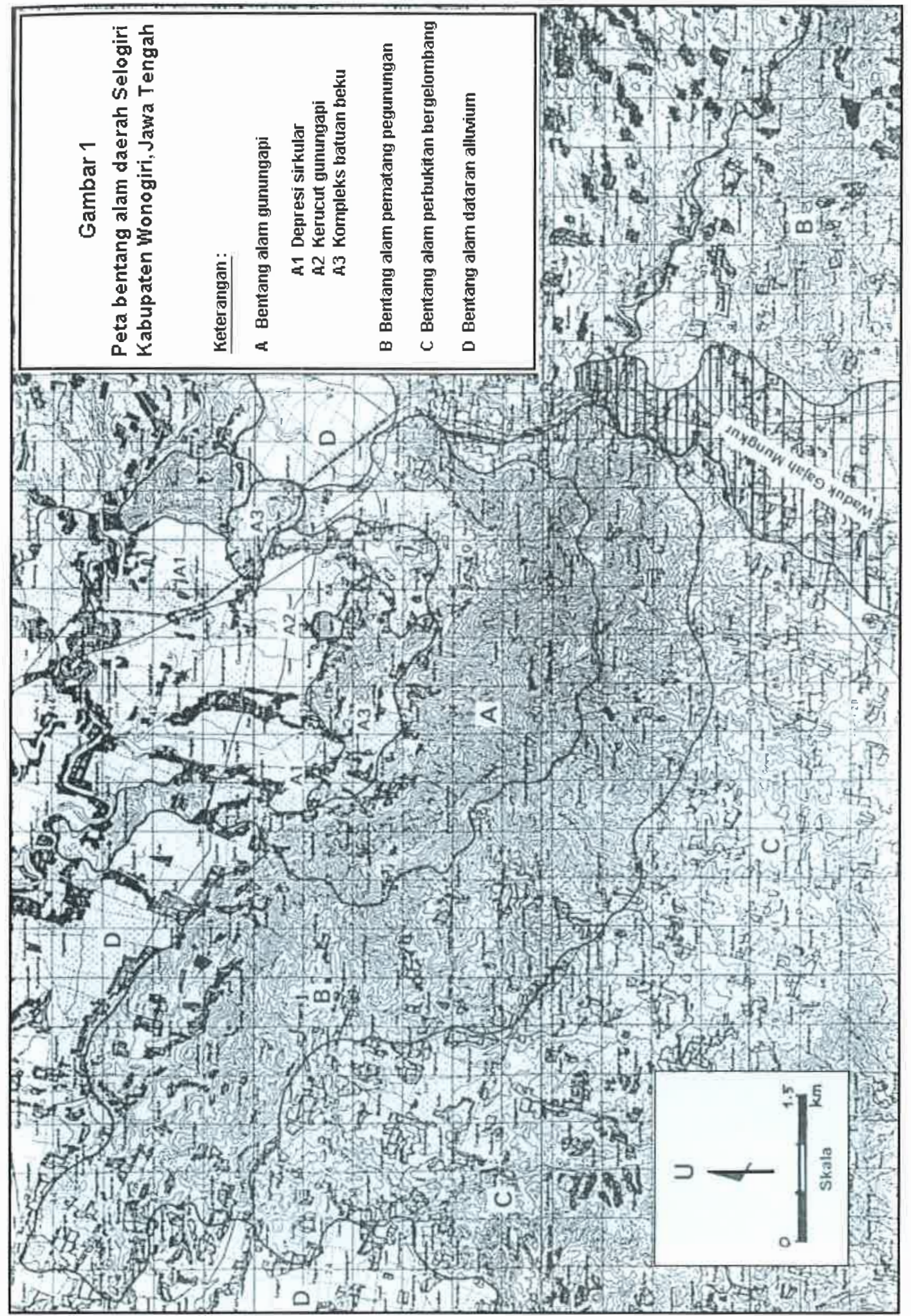




\section{STUDI PARAMETER PEMBENTUK FASIES GUNUNGAPI}

Daerah Selogiri merupakan bagian dari suatu bentangalam gunungapi dan termasuk ke dalam Jalur Pegunungan Selatan Jawa; dibentuk oleh satuansatuan stratigrafi tidak resmi yang terdiri dari breksi gunungapi andesitik, tuf dasitik, andesit porfir, diorit, aglomerat, batugamping dan alluvium. Upaya pengenalan bentangalam dan pengujian ciri-ciri fisik satuan-satuan stratigrafi terkait menjadi penting dilakukan terutama untuk identifikasi fasies gunungapi di daerah Selogiri dan sekitarnya.

\section{Bentangalam gunungapi dan struktur geologi}

Secara morfologi daerah Selogiri dibentuk oleh bentangalam (Gambar 1 dan Foto 1 ) yang terdiri atas:

A. Gunungapi yang dibagi menjadi depresi sirkular (A1), kerucut gunungapi (A2) dan kompleks batuan beku (A3).

B. Pematang pegunungan

C. Perbukitan bergelombang

D. Dataran aluvium.

Bentangalam pertama memperlihatkan suatu depresi berbentuk menyerupai lingkaran dengan garis tengah kira-kira $8 \mathrm{~km}$, yang terletak di sebelah timur laut terban dari sistem sesar normal berarah baratlauttenggara. Di bagian selatan depresi ini ditempati oleh batuan andesit dan diorit, dimana lebih dari separuh bagian utara daerah ditutupi oleh endapan aluvium. Depresi tersebut dikelilingi oleh jurang yang dibentuk oleh breksi gunungapi andesitik dan beberapa bukit kecil yang merupakan bentukan batuan andesit atau diorit. Sebagian bukit kecil ini memperlihatkan bentuk bentang alam kerucut gunungapi seperti yang dijumpai di G.Tenongan. Distribusi tubuh-tubuh batuan beku diduga menggambarkan hubungan kegiatan magmatik dan pola bukaan struktur dalam suatu kaldera gunungapi.

Pematang pegunungan dibentuk oleh breksi gunungapi dan tuf. Sesar normal berarah baratlauttenggara diduga terjadi setelah proses vulkanisma dan telah membentuk sembul di bagian tengah daerah pengamatan, yang dibatasi oleh terban-terban di sebelah timurlaut dan baratdaya. Sementara bentangalam perbukitan bergelombang terletak di bagian terban dari sistem sesar normal, yang dibentuk oleh struktur sinklinorium dan antiklinorium dari satuan batuan tuf dan batugamping. Ciri-ciri batuan gunungapi dan batuan beku (Gambar 2)

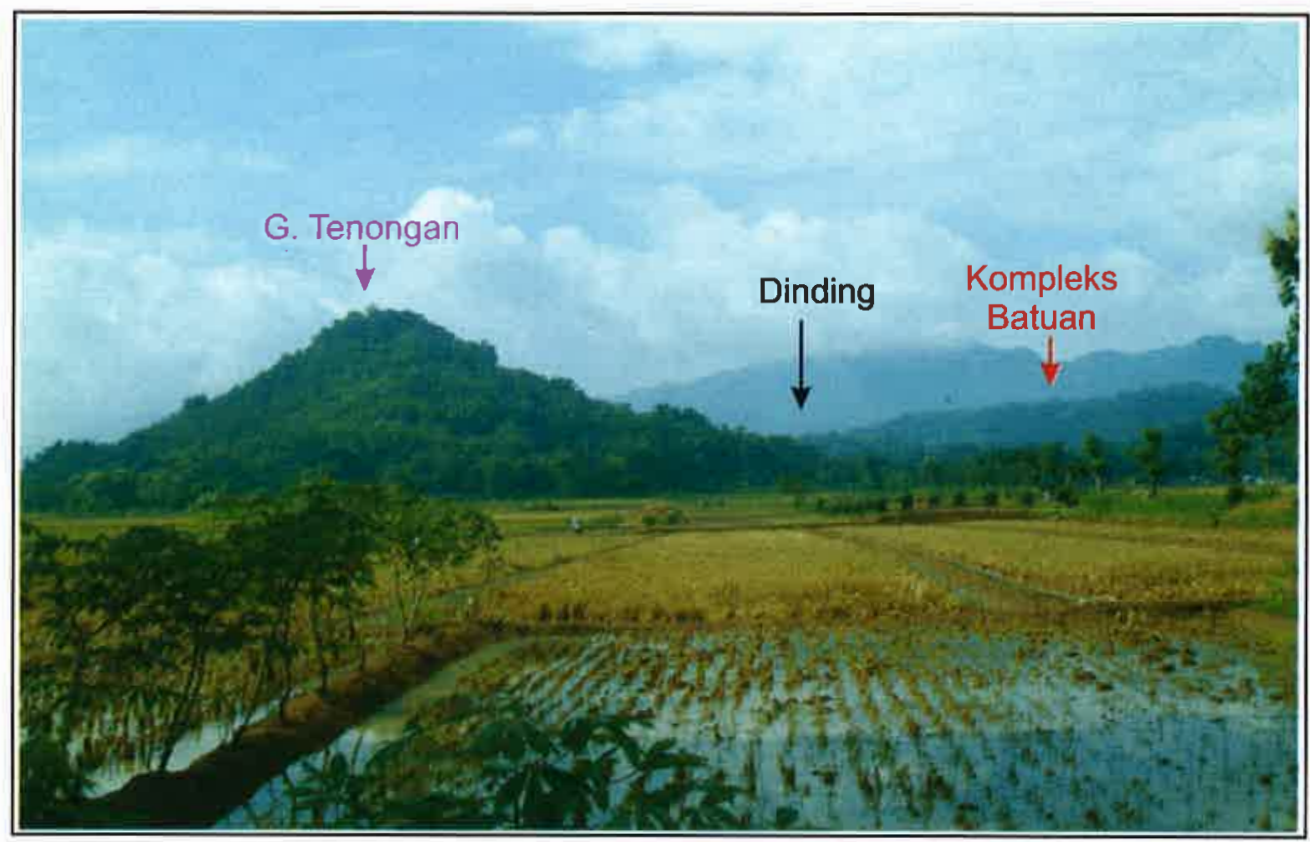

Foto 1

Kenampakan bentangalam kerucut gunungapi (G.Tenongan) dengan latar belakang dinding kaldera, dilihat dari arah Selogiri 


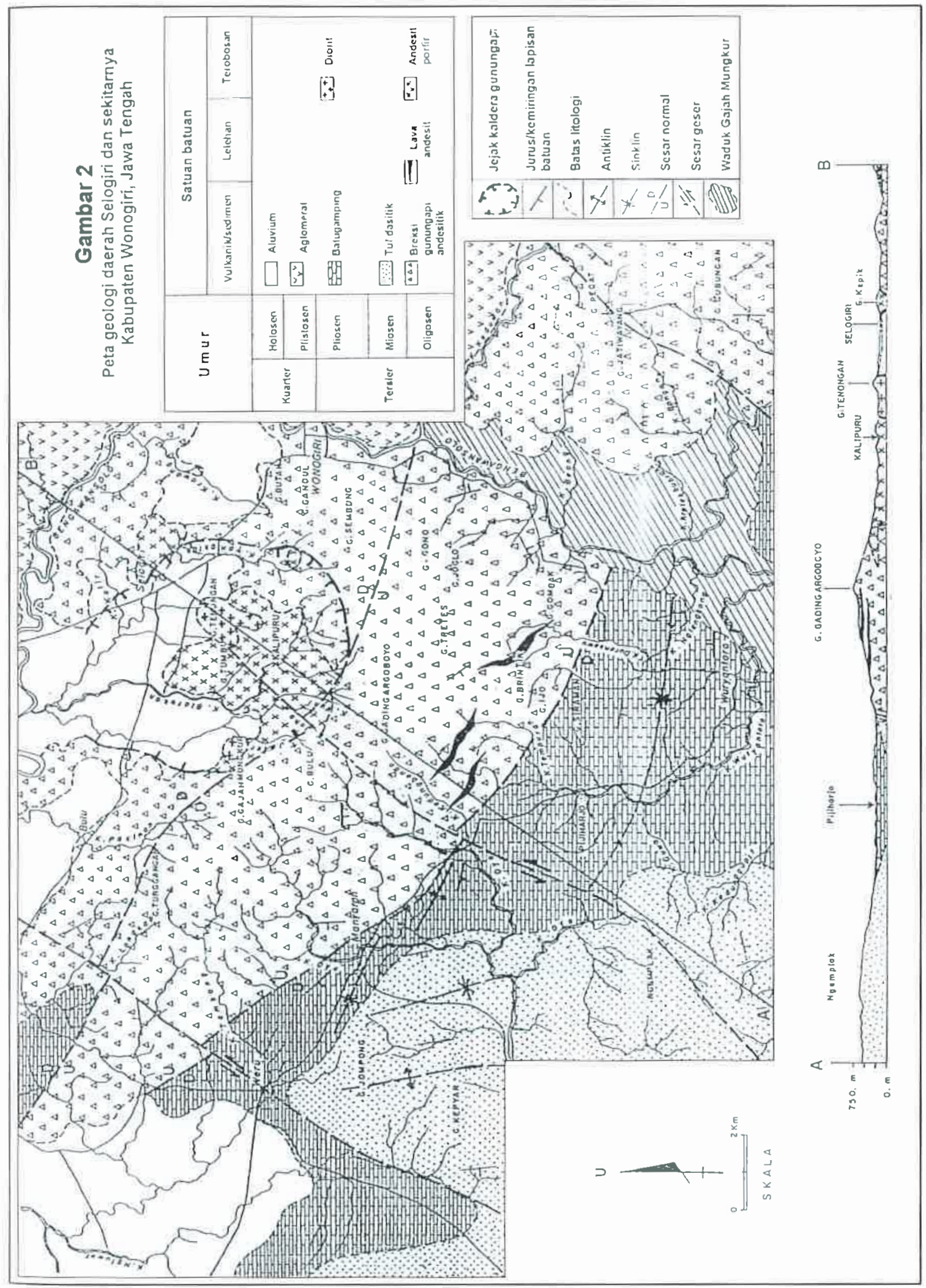




\section{Breksi gunungapi}

Satuan stratigrafi ini tersebar luas terutama dibagian utara daerah pengamatan dan menempati jalur pegunungan berarah baratlaut-tenggara. Batuan umumnya berwarna kelabu hingga kelabu kehijauan, disusun oleh terutama clasts (potongan batuan) dan matriks tuf. Clast berukuran kerikil hingga bongkah, bersudut - membundar tanggung, sebagian besar bersusunan andesit dan setempat ditemukan dasit dan tuf terkersikkan; tertanam dalam masadasar tuf. Ketebalan lapisan breksi dari tebal hingga sangat tebal dan umumnya telah terubah terkloritkan.

Di bagian bawah satuan ini setempat-setempat disisipi oleh lava andesit terkloritkan, dengan tekstur auto-breksi pada permukaannya. Sementara di bagian atas disisipi setempat-setempat oleh lapisan tipis tuf berbatuapung dengan tekstur graded dan laminasi. Breksi gunungapi berubah secara berangsur menjadi tuf dengan ciri struktur aliran debris pada zona sentuhnya. Setempat-setempat lava andesit menyisip di antara lapisan tuf dan telah mengalami ubahan terkloritkan.

Ciri-ciri satuan stratigrafi ini teramati serupa dengan Formasi Mandalika yang diendapkan pada Oligosen - Miosen Awal (Surono dkk., 1992).

\section{Andesit}

Singkapan batuan beku berbentuk kubah dengan struktur berlembar di bagian atasnya, hanya ditemukan di lingkungan depresi sirkular. Ciri batuan bertekstur porfiritik dan berwarna kelabu kehijauan hijau dan porfiritik; disusun oleh fenokris plagioklas dan piroksen (berukuran butir maksimum menengah) yang tertanam dalam masadasar mikrolit plagioklas, piroksen, kuarsa dan mineral oksida. Kristal-kristal piroksen menyerupai jarum mencapai jumlah sebesar $10 \%$ dari volume total dan memperlihatkan orientasi teratur mengikuti garis aliran. Diduga batuan ini merupakan terobosan batuan beku yang bersamaan dengan vulkanisma yang menghasilkan endapan piroklastik breksi dan tuf.

\section{Tuf dasitik}

Satuan stratigrafi ini tersebar di sebelah baratdaya tebing memanjang berarah baratdayatimurlaut searah satuan breksi gunungapi, bercirikan perulangan lapisan tuf bertekstur laminasi dan graded. Batuan berwarna kelabu terang-kehijauan bersusunan terutama kristal kuarsa dan felspar, yang dapat dikategorikan ke dalam tuf kristal dasitik. Ketebalan lapisan beragam dari sangat tipis hingga sangat tebal, dengan perubahan secara berangsur ukuran butir lapili hingga halus dari bagian bawah ke arah atas.

Bagian atas satuan stratigrafi ini didominasi perulangan lapisan bertekstur laminasi dan graded dengan setempat-setempat mengandung batuapung dan sisipan tipis batulempung/serpih. Satuan ini diendapkan di atas breksi gunungapi dan mempunyai ciri-ciri yang serupa dengan Formasi Semilir berumur Miosen Awal - Tengah (Surono dkk., 1992).

\section{Diorit}

Singkapan batuan merupakan terobosan berbentuk kerucut gunungapi yang terletak di bagian pusat depresi sirkular. Ciri-ciri batuan berwarna kelabu, hampir tidak terubah hidrotermal, porfiritik, disusun oleh fenokris plagioklas (ukuran butir kasarsangat kasar) dan masadasar mikrolit-mikrolit plagioklas, kuarsa dan sedikit mineral mafik. Tubuh diorit diduga berupa stock yang menerobos breksi gunungapi dan andesit. dengan ciri-ciri serupa Dioril Pendul yang berumur Pliosen (Mahfi, 1984).

\section{Aglomerat}

Satuan stratigrafi ini menempati daerah kecil di sebelah timurlaut Bengawan Solo dan S.Keduwan. disusun oleh clasts basaltik dan matriks tuf ; dengan sisipan lava basalt di antara lapisan tuf dan di bagian atas didominasi oleh tuf berbatuapung. Diduga aglomerat ini merupakan produk erupsi G.Lawu, yang diendapkan secara tidak selaras di atas breksi gunungapi pada Plistosen Akhir (Bemmelen, 1949).

\section{INTERPRETASI HUBUNGAN MODEL FASIES GUNUNGAPI DAN MINERALISASI}

Hasil identifikasi terhadap parameter pembentuk fasies gunungapi menuntun ke arah dugaan sebagai berikut :

- Batuan gunungapi di daerah Selogiri dapat dikategorikan ke dalam sekwen susunan batuan dari gunungapi komposit berdasarkan kenampakan perlapisan batuan yang didominasi piroklastik dan lava.

- Depresi sirkular merupakan jejak suatu kaldera gunungapi yang dihasilkan oleh erupsi magmatik (Plinian). Semburan magma ke permukaan berupa ledakan dan lelehan, sehingga menghasilkan endapan jatuhan seperti breksi gunungapi dan tuf 

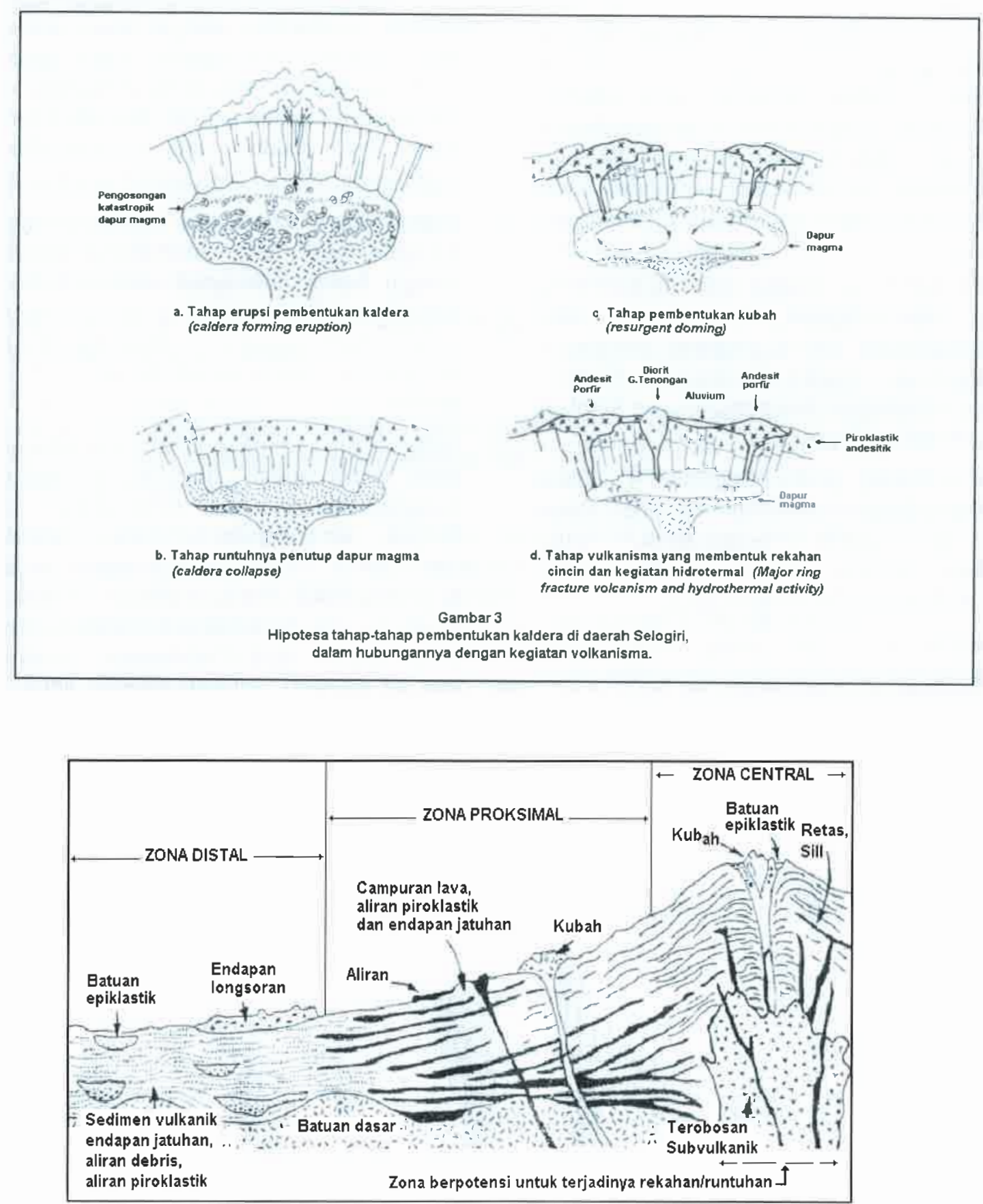

Model fasies vulkanik menurut William dan McBirney (1972)

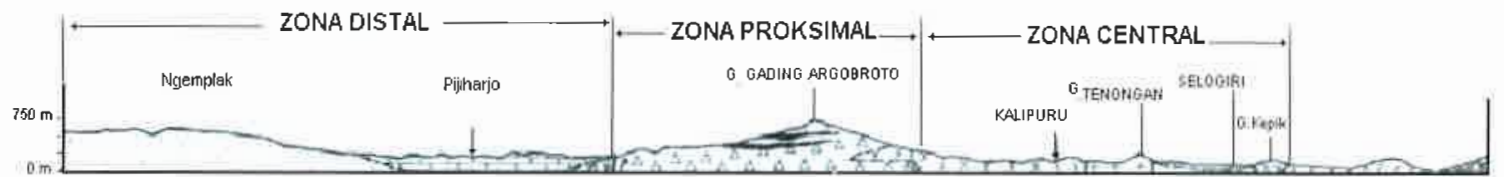

\section{Gambar 4}

Fasies vulkanik di daerah Selogiri, Kabupaten Wonogiri, Jawa Tengah dibandingkan dengan Model Fasies Vulkanik dari William dan McBirney (1972). 
sirkular tersebut.

- Sebaran secara sirkular dari batuan andesit merupakan indikasi bahwa kegiatan penerobosan batuan beku tersebut mengikuti pola rekahan berbentuk cincin (ring fractures), sebagai bagian dari tahap pembentukan kubah (resurgent doming) dan vulkanisma pembentukan rekahan besar berbentuk cincin (major ring-fracture volcanism) (Gambar 3).

- Tuf dasitik bertekstur graded dan laminasi serta bersisipan lapisan-lapisan tipis batulempung/ serpih menandakan bahwa endapan piroklastik tersebut merupakan produk gunungapi yang telah mengalami transportasi dan pengendapan kembali jauh dari sumber asalnya.

Sayatan melintang geologi (Gambar 4) dibuat sebagai data penunjang untuk interpretasi model fasies gunungapi di daerah pengamatan, yang disebandingkan dengan acuan model fasies berdasarkan William dan McBirney (1972).

Dari kesebandingan tersebut maka model fasies gunungapi di daerah Selogiri dapat diinterpretasikan sebagai berikut :
1. Daerah depresi sirkular gunungapi atau jejak kaldera diperkirakan sebagai fasies central atau vent, ditandai oleh sebaran breksi gunungapi, terobosan andesit (kubah) yang mengisi rekahan tepi kaldera (sirkular/cincin) dan diorit (stock) di bagian pusat kaldera serta aluvium. Fasies ini mempunyai sebaran berdiameter kira-kira $8,0 \mathrm{~km}$.

2. Daerah yang dibentuk oleh breksi gunungapi dan tuf (piroklastik) serta lava andesit diperkirakan sebagai fasies proksimal, dimana ketiga jenis batuan tersebut merupakan hasil pengendapan primer pada kegiatan vulkanisma. Fasies ini mempunyai sebaran sejauh $2.0 \mathrm{~km}-15 \mathrm{~km}$ dari kaldera.

3. Endapan tuf bercirikan kontinuitas sebaran yang besar secara lateral, diperkirakan sebagai hasil transport sekunder dan pengendapan kembali. Sisipan lempung/serpih dalam lapisan tuf menandakan bahwa pengendapan terjadi di lingkungan laut yang disebabkan transportasi oleh media air dan dipindahkan kembali dengan jarak yang jauh dari sumbernya (subaqueous transportation). Lingkungan ini dapat dikategorikan sebagai fasies distal berdasarkan

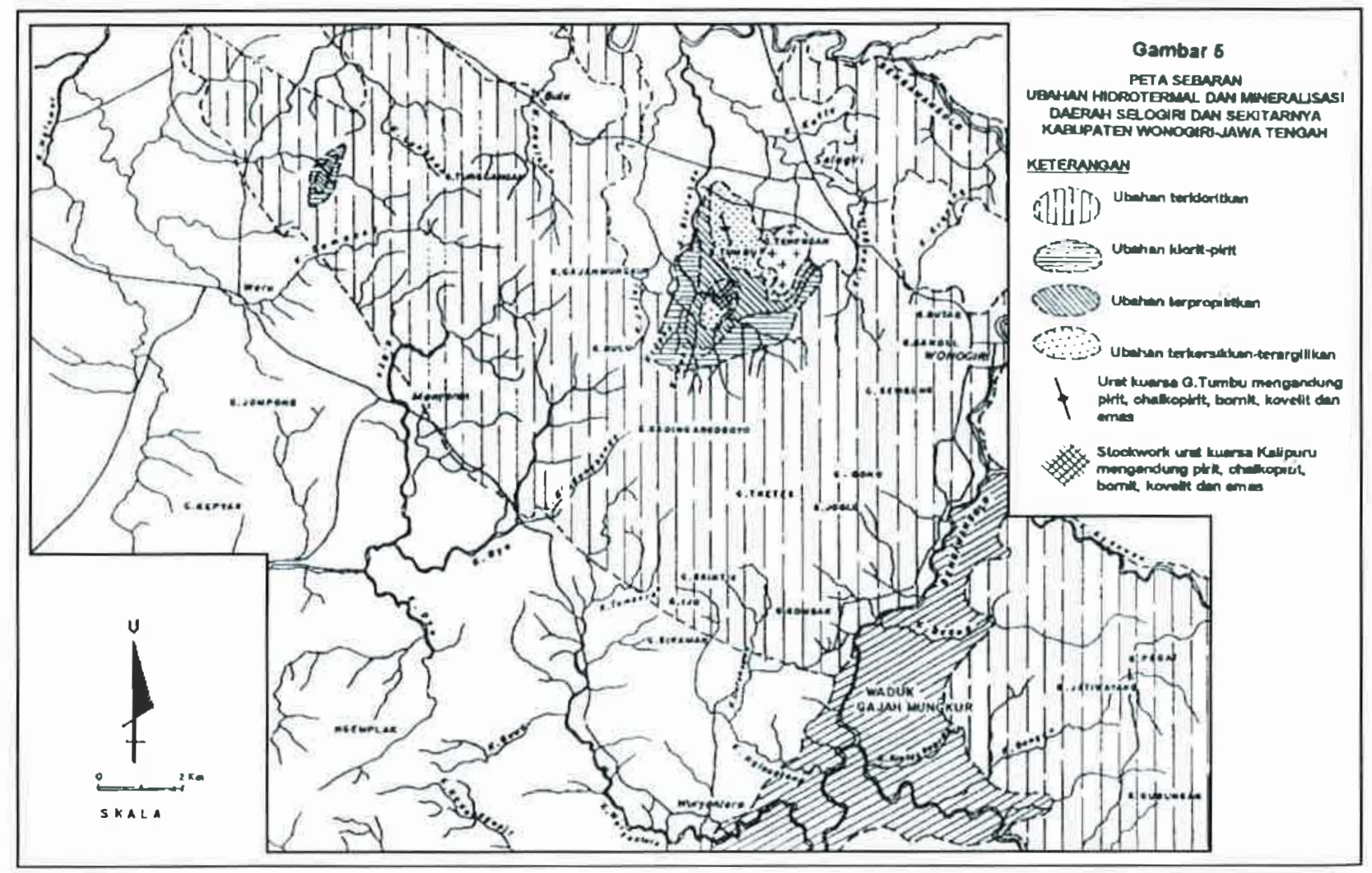

(Dannv Z. Herman dkk.. 1996) 
jarak sebaran sejauh $5-15 \mathrm{~km}$ dari daerah kaldera. Sementara kehadiran batugamping memperkuat dugaan tentang lingkungan pengendapan laut atau cekungan laut, dan diendapkan di bagian terban dari sistem sesar normal.

Hubungan antara fasies gunungapi dengan gejala ubahan hidrotermal dan mineralisasi yang intensif (Gambar 5) terjadi pada daerah depresi sirkular karena adanya faktor-faktor pengendali berupa :

$\square$ Terobosan diorit diduga sebagai sumber fluida hidrotermal dan larutan pembawa mineralisasi

$\square$ Pola rekahan yang berperan sebagai saluran jalan keluarnya fluida hidrotermal dan larutan pembawa mineralisasi untuk terjadinya mineralisasi di daerah depresi sirkular tersebut.

Karakteristik mineralisasi emas epitermal di daerah ini terutama berupa stockwork urat kuarsa dan juga tersebar (dissemination) dalam batuan andesit terubah terkersikkan-terargilikkan. Urat kuarsa mengandung emas, chalkopirit, bornit, kovelit dan pirit. Zona ubahan tersebut berubah ke arah luar berturut-turut menjadi propilitik, klorit-pirit dan terkloritkan.

\section{KESIMPULAN}

Studi tentang fasies gunungapi dapat dilakukan sebagai bagian dari kegiatan eksplorasi mineral dan dapat digunakan untuk membantu pemahaman keterjadian mineralisasi yang berkaitan dengan vulkanisma dan magmatisma.

Bertolak dari letak wilayah Indonesia yang sebagian besar berada dalam sabuk gunungapi/magmatik, maka pengetahuan tentang model fasies gunungapi dapat diterapkan untuk menandai daerah-daerah berpotensi termineralisasi dalam lingkungan gunungapi/magmatik atau dapat disebut konsep pusat gunungapi (Concept of Volcano Centre).

Daerah depresi sirkular di Selogiri diduga sebagai jejak kaldera yang diinterpretasikan sebagai wilayah fasies central/vent dalam suatu bentangalam gunungapi komposit. Lingkungan dimana kondisi geologi, pola rekahan intensif dan kegiatan penerobosan batuan-batuan beku menjadi pengendali terjadinya ubahan hidrotermal dan mineralisasi karena terletak pada pusat kegiatan vulkanisma, magmatisma dan tektonisma.

\section{UCAPAN TERIMA KASIH}

Terima kasih disampaikan kepada Kepala Kelompok Kerja Konservasi, Pusat sumber Daya Geologi yang telah mengizinkan penggunaan fasilitas perangkat komputer untuk kelancaran penulisan makalah ini. Penghargaan yang tinggi kepada Sutrisno, M.Sc dan Ir. Bambang Pardiarto yang telah menyediakan waktu untuk berdiskusi dan memberi saran perbaikan ilustrasi/gambar dan isi makalah.

\section{PUSTAKA TERPAKAI}

Bemmelen, R.W.Van.; 1949. The Geology of Indonesia, V.IA, Martinus Nijhoff, The Hague, 742 pages.

Herman, Danny Z.; Gunradi, R. dan Sudarya, S.; 1996. Hasil Eksplorasi Mineral Logam di Selogiri, Wonogiri, Propinsi Jawa Tengah; dalam Paper Spesial Kolokium : Hasil Eksplorasi Cebakan Bijih Logam, Geokimia dan Geofisika; No.11, ISSN : 0216-1811, Bandung, March 13-1996; Proyek Eksplorasi Mineral Logam, Industri dan Batubara; Direktorat Jenderal Geologi dan Sumber Daya Mineral, Departemen Pertambangan dan Energi RI.

Mahfi, A.; 1984. A Paleomagnetic of Miocene and Eocene Rocks from Central Java, Indonesia. Unpublished Thesis, Master of Arts : University of California; dalam Geologi Lembar Surakarta-Giritontro, Java. Republik Indonesia, Dept.Pertambangan dan Energi, Direktorat Jenderal Geologi dan Sumberdaya Mineral, PPPG.

Self, S; 1982d. Nature of Subaerial Pyroclastic Deposits Based on A Facies Concept, in Volcanology and Mineral Deposits, Edited by Wood et al, Ontario Geological Survey, Miscellaneous Paper 129, Ministry of Northern Development and Mines, p.5. 


\section{Buletin Sumber Daya Geologi Volume 1 Nomor 1 - 2006}

Surono; Tuha, B. dan Wirjosujono, S.; 1992. Geologi Lembar Surakarta-Giritontro, Java; Skala 1:100.000, Republik Indonesia, Dept.Pertambangan dan Energi, Direktorat Jenderal Geologi dan Sumberdaya Mineral, PPPG.

Trowell, N.F.; 1986, Stratigraphic Correlation Techniques, in in Volcanology and Mineral Deposits, Edited by Wood et al, Ontario Geological Survey, Miscellaneous Paper 129, Ministry of Northern Development and Mines, p.41-47.

William, H.; 1941. Calderas and Their Origin, in Volcanology and Mineral Deposits, Edited by Wood et al, Ontario Geological Survey, Miscellaneous Paper 129, Ministry of Northern Development and Mines, p.117.

, and McBirney, A.R.; 1979. Volcanology, in Volcanology and Mineral Deposits, Edited by Wood et al, Ontario Geological Survey, Miscellaneous Paper 129, Ministry of Northern Development and Mines, p. 28.

Wood, J. and Wallace, H.; 1986. Volcanology and Mineral Deposits, Edited by Wood et al, Ontario Geological Survey, Miscellaneous Paper 129, Ministry of Northern Development and Mines, 183 pages. 